\section{Aspectos médicos, éticos y legales de la criopreservación de embriones humanos}

\author{
JUAN PABLO BECA ${ }^{1}$, ALBERTO LECAROS ${ }^{1}$, PATRICIO GONZÁLEZ ${ }^{2}$, \\ PABLO SANHUEZA ${ }^{2}$, BORISLAVA MANDAKOVIC ${ }^{3}$
}

\section{Medical, ethical and legal issues in cryopreservation of human embryos}

Embryo cryopreservation improves efficiency and security of assisted reproduction techniques. Nonetheless, it can be questionable, so it must be justified from technical, legal and ethical points of view. This article analyses these perspectives. Embryo cryopreservation maximizes the probability of pregnancy, avoids new ovary stimulations and reduces the occurrence of multiple gestations. There is consensus that the in vitro embryo deserves legal protection by its own, although not as a newborn. Very few countries prohibit embryo cryopreservation based on the legal duty to protect human life since fecundation. Those countries that allow it, privilege women's reproductive rights. In Chile and in Latin America, no laws have been promulgated to regulate human assisted reproduction. The moral status of the embryo depends on how it is considered. Some believe it is a potential person while others think it is just a group of cells, but all recognize that it requires some kind of respect and protection. There is lack of information about the number of frozen embryos and their final destination. As a conclusion the authors propose that women or couples should have the right to decide autonomously, while institutions ought to be clear in their regulations. And the legislation must establish the legal status of the embryo before its implantation, the couples' rights and the regulation of the embryo cryopreservation. Personal, institutional or legal decisions must assume a concept about the moral status of the human embryo and try to avoid their destruction or indefinite storage.

(Rev Med Chile 2014; 142: 903-908)

Key words: Cryopreservation; Embryo dispositions; Embryo research; Legislation; Moral obligations; Reproductive techniques.

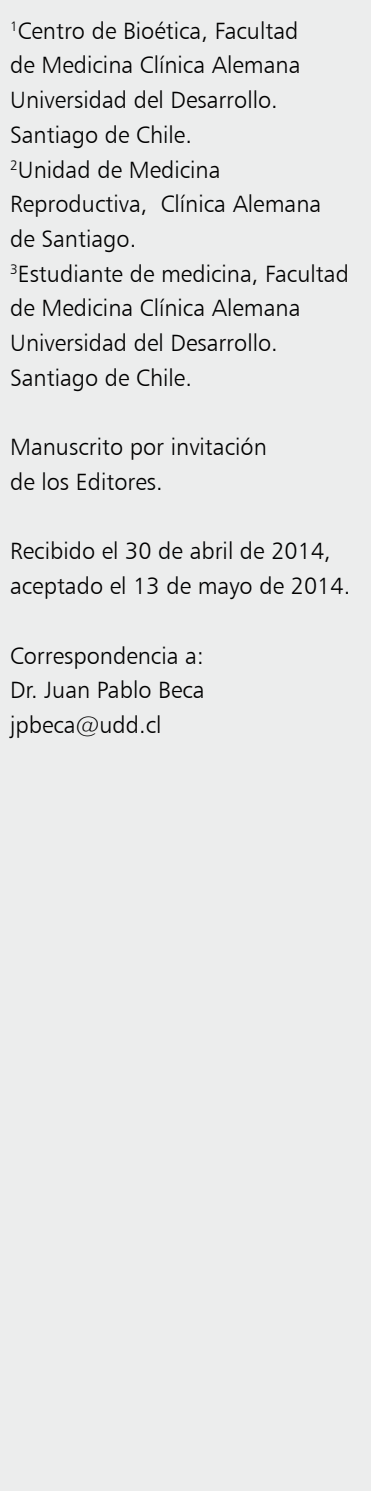

$\mathrm{E}$ 1 nacimiento de Louise Brown en 1978 gracias a la fecundación in vitro (FIV) marcó un hito en la historia del tratamiento de la infertilidad de la pareja humana ${ }^{1}$. Durante los primeros años, la FIV se realizaba en un ciclo ovárico natural y la aspiración del óvulo se efectuaba mediante laparoscopia. Desde la década de 1980, se agregó la estimulación ovárica para recuperar más óvulos, haciendo posible obtener más de un embrión. Posteriormente, con la asociación de gonadotrofinas recombinantes con antagonistas y agonistas de la hormona liberadora de gonadotrofinas $(\mathrm{GnRh})$, se logró mejores resultados en la recuperación de ovocitos. La inseminación de un número mayor de óvulos permite mejorar la eficiencia de la FIV al obtener más embriones para ser transferidos. Sin embargo, esto se traduce en un aumento de los embarazos múltiples con las consecuencias negativas asociadas al mayor riesgo de prematuridad y mayor riesgo materno. Para disminuir estos riesgos surgió la alternativa de congelar los embriones no transferidos, repor- 
tándose en 1983 el primer embarazo derivado de un embrión criopreservado ${ }^{2}$.

La criopreservación de embriones es una herramienta habitual en técnicas de reproducción asistida. Esta técnica permite maximizar las probabilidades de embarazo por cada extracción ovocitaria, al reservar los embriones sobrantes para ser utilizados en un siguiente ciclo sin requerir de una nueva estimulación ovárica y culdocentesis ${ }^{3}$. De esta manera se mejora la eficiencia y la seguridad en la aplicación de las técnicas de reproducción asistida. La alternativa más reciente de la criopreservación de óvulos es menos eficiente y se usa más bien para la postergación de fertilidad, por lo que aun no ha reemplazado a la conservación de embriones.

Una de las principales complicaciones de las técnicas de reproducción asistida de alta complejidad es el embarazo múltiple. La principal herramienta para disminuir esta complicación es la reducción del número de embriones a transferir, llegándose a recomendar la transferencia electiva de sólo un embrión seleccionado de una cohorte. Los embriones no seleccionados para ser transferidos pueden ser criopreservados para su posible transferencia posterior, lográndose así tasas de embarazo múltiple de $0 \%{ }^{4}$.

Sin embargo, la criopreservación de embriones plantea interrogantes no sólo en lo técnico, sino también en lo ético. Es entonces necesario analizar el estatuto moral del embrión humano y los deberes de respeto y protección que implica. Con el propósito de contribuir a aclarar estas dudas, en este artículo, junto con las razones médicas para la criopreservación de embriones, se revisa la regulación jurídica y el estatuto moral del embrión humano.

\section{Eficiencia de la criopreservación de embriones humanos}

Las técnicas de reproducción asistida de alta complejidad con hiperestimulación ovárica controlada permiten aspirar ovocitos, seleccionarlos y realizar la fertilización in vitro clásica o la inyección intracitoplasmática de espermatozoides (ICSI). Los embriones desarrollados pueden ser seleccionados para ser transferidos al útero y los embriones sobrantes pueden ser criopreservados para ser transferidos en un ciclo posterior. Otra al- ternativa es la FIV/ICSI de un número limitado de ovocitos con el fin de lograr un número definido de embriones que serán transferidos en su totalidad al útero, evitando el desecho y la criopreservación de embriones. Sin embargo, para analizar la eficiencia de las técnicas de criopreservación embrionaria, hay que considerar que existen numerosas variables que la determinan. Probablemente el factor más importante es el hecho de transferir un embrión seleccionado por su calidad en una cohorte, criopreservando los restantes para ser transferidos más adelante si no hubo éxito ${ }^{5}$.

La alternativa más usada en los centros de reproducción asistida es la criopreservación de embriones. La European Society of Human Reproduction and Embriology (ESHRE) ha informado que durante el año 2008 se realizaron en Europa 405.091 ciclos de alta complejidad (FIV/ICSI), con una tasa de $20,7 \%$ de recién nacidos por ciclo iniciado. Si bien no se informa en cuántos ciclos iniciados se realizó criopreservación embrionaria, podemos inferir que en 70 a $80 \%$ de ellos hubo criopreservación de al menos un embrión. Considerando el mismo reporte, durante el mismo año hubo 97.120 ciclos de descongelación embrionaria con transferencia uterina, con una tasa de $13,7 \%$ de recién nacidos por ciclo de embriones descongelados ${ }^{6}$.

Muy pocos centros realizan FIV/ICSI con un número limitado de ovocitos por ciclo, por lo que no es posible conocer grandes casuísticas. En esa línea, la experiencia italiana aporta la mayor evidencia, pues entre los años 2004 y 2010 existió una prohibición legal de realizar criopreservación embrionaria, limitando el número de ovocitos a fertilizar a 3 por ciclo. En esta modalidad, la mejor casuística publicada corresponde a estudios multicéntricos con tasa de recién nacidos por transferencia de $21,6 \%$ por ciclo fresco (embriones no congelados). La alternativa a la criopreservación embrionaria en ese período de estudio fue la criopreservación de los ovocitos sobrantes, reportándose tasas de recién nacido de $11,6 \%$ por transferencia ${ }^{7}$. En un contexto comparable, en la Unidad de Medicina Reproductiva de Clínica Alemana de Santiago no se realiza criopreservación embrionaria y se limita el número de ovocitos a inseminar, dependiendo de la edad y la historia clínica de cada caso. Los resultados (aún no publicados) muestran tasas de $22 \%$ de recién nacidos por ciclo entre los años 2007 y 2012, con una tasa 
de embarazo múltiple de $24 \%$, de los cuales sólo $14 \%$ del total fue de alta multigestación (tres o cuatro recién nacidos).

Si bien, con o sin criopreservación de embriones, las tasas de recién nacidos por transferencia en el ciclo fresco son relativamente similares, la diferencia es significativa en el ciclo de descongelamiento posterior. La descongelación ovocitaria ofrece menores tasas de recién nacidos que la descongelación embrionaria ( $12,5 \%$ vs $16,4 \%$, CI 95\%), difiriendo también en las tasas de embarazos múltiples 8 .

\section{Visión jurídica de la criopreservación de embriones}

Hay consenso en la doctrina y en el derecho comparado que el embrión conservado in vitro merece protección jurídica por su propio interés y no por ser un objeto de interés o una mera cosa. En casi todos los ordenamientos jurídicos y en la jurisprudencia constitucional comparada, la protección de la vida del que está por nacer y la del recién nacido tiene diferente extensión e intensidad, sin conceder a la vida humana in vitro la misma protección que se le da a un recién nacido. El punto relevante para el Derecho es determinar cuál interés tiene mayor peso: el interés de la vida del embrión in vitro o los intereses de la mujer o de la pareja.

Con respecto a la regulación jurídica sobre la creación de embriones excedentes y su criopreservación, una minoría de las leyes europeas (v. gr. Alemania, Austria, Suiza e Italia) prohíbe estas prácticas, fundadas en un deber de protección jurídica unitaria de la vida humana desde la fecundación. En cambio, la mayoría (v. gr. Reino Unido, España, Bélgica, Francia) las autoriza apoyadas en una protección jurídica gradual del embrión: menos al embrión preimplantacional in vitro que al embrión implantado, privilegiando los derechos reproductivos de la mujer. La regla general en estas últimas legislaciones es entregar a los progenitores la disposición de los embriones criopreservados para su uso en futuras transferencias y cuando éste no sea su destino pueden, durante plazos definidos, donarlos a terceros con fines reproductivos, autorizar su utilización para fines de investigación o pedir su destrucción.

Dentro de las legislaciones más restrictivas cabe destacar la ley suiza que, si bien prohíbe la criopreservación de embriones, permite la de pronúcleos para que sean utilizados exclusivamente con fines reproductivos por los progenitores, prohibiendo su donación a otras parejas o destinarlos a la investigación. Para evitar la criopreservación embrionaria las leyes alemana (1990), austríaca (1992), suiza (1998) e italiana (2004) establecen un límite de 3 óvulos a fecundar por cada ciclo reproductivo, con la obligación de que todos ellos sean transferidos ${ }^{9-11}$. En todo caso la prohibición de criopreservación embrionaria no es absoluta. Así, por ejemplo, la ley italiana contempla una excepción que autoriza criopreservar por un tiempo limitado cuando por causas imprevistas y de fuerza mayor relativas a la salud de la mujer resulte imposible hacer la transferencia ${ }^{11}$. Cabe precisar que en 2009 la Corte Constitucional italiana impugnó la prohibición general de esta ley de criopreservar por considerar que atenta contra el derecho a la salud de la mujer ${ }^{12}$. En Alemania, se sanciona la trasferencia de un embrión sin el consentimiento de la mujer por lo que, en caso de revocación, el médico está autorizado para criopreservar los embriones no transferidos?. En esta materia, el Parlamento Europeo ha emitido dos resoluciones recomendando que sólo se criopreserven embriones humanos por un tiempo limitado para la implantación destinada al embarazo de la mujer, y que se utilicen técnicas de inseminación artificial humana que no produzcan un número excesivo de embriones ${ }^{13}$.

En Chile, al igual que en los demás países latinoamericanos, aún no se promulga una ley especial sobre reproducción humana asistida. Se han tramitado dos proyectos de ley sobre esta materia, actualmente archivados, y ambos tipificaban como delito tanto la criopreservación y destrucción de embriones como su utilización para fines distintos de la reproducción humana ${ }^{14}$.

En la discusión jurídica internacional más reciente, la Corte Interamericana de Derechos Humanos introdujo el concepto de que la "concepción" equivale a la implantación y que, sólo una vez que se ha demostrado la existencia de un embarazo, el embrión humano debe ser tratado como persona ${ }^{15}$, aunque al embrión preimplantacional se le reconoce un grado de protección jurídica. Este significado del término concepción se fundamentó en la definición de la Real Academia de la Lengua que define concebir como "quedar 
preñada una hembra". Sin embargo, el lenguaje científico no lo considera así y tanto las palabras clave de la U.S. National Library of Medicine como la literatura científica consideran que "conception" y "fertilization" (fecundación) son equivalentes ${ }^{16}$.

\section{Estatuto moral del embrión humano}

La discusión acerca del estatuto moral del embrión humano admite diferentes posiciones. En general se acepta que la persona humana tiene dignidad en sí misma y que por eso tiene derechos que puede ejercer y que todos tenemos el deber de respetar. Sin embargo, esto es discutido en su aplicación al no nacido y más aún para un embrión preimplantacional. Los deberes morales con el embrión dependen de cómo se le considere, lo cual puede ser: a) igual que una persona adulta por ser vida humana y persona potencial; b) como un grupo celular o tejido; c) como una entidad en situación intermedia con la cual existen obligaciones morales especiales de protección.

Nadie puede asegurar que un embrión preimplantacional sea persona, pero es indiscutible que lo será si se permite y no se interrumpe su desarrollo. Por eso se habla de "persona potencial" y también del deber moral de respetarlo "como persona". El concepto de "persona potencial" requiere distinguir la potencialidad como mera posibilidad de llegar a ser persona de la potencialidad como capacidad propia del embrión para alcanzar esa realidad. En el caso del embrión preimplantacional, algunos consideran que aún no tiene la capacidad para que su nuevo genoma se exprese continuando su desarrollo y definiendo finalmente su realidad personal. Esta capacidad la adquiere el embrión con el aporte epigenético que se inicia durante la implantación, después del $6^{0}$ día ${ }^{17}$. De esta manera el embrión en su fase preimplantacional no es persona en acto y tampoco sería tan claramente persona en potencia ${ }^{18,19}$.

Si el embrión no es persona, no es sujeto de derechos. Pero, en el otro extremo, casi nadie lo considera igual a cualquier célula o a un grupo celular que podrían ser tratados como un objeto. $\mathrm{Al}$ menos se le reconoce como vida humana que llegará a ser persona si su desarrollo continúa. Por lo tanto, sería una entidad en una condición intermedia entre ser "algo" y ser un "alguien", con un valor especial vinculado al de la persona humana.
Si aún las cosas que tienen valor, como por ejemplo una obra de arte, deben ser protegidas, al valorar al embrión como vida humana en su fase inicial de desarrollo, se le debería reconocer al menos una dignidad que se ha denominado "dignidad conferida". Es razonable aceptar entonces que ante el embrión humano tenemos obligaciones de protección. Estas obligaciones, expresadas en términos de principios bioéticos deberían fundamentarse aplicando los principios de No Maleficencia y de Justicia.Y por ser el embrión humano una entidad que posiblemente llegará a ser una persona, desde la ética de la responsabilidad, también existen deberes de protección como los hay con las generaciones futuras ${ }^{20}$.

La pregunta ética para el caso de las técnicas de medicina reproductiva es si la criopreservación de embriones cumple con esta obligación moral de protección. Las diferentes respuestas valoran menos al embrión que a los fetos o recién naci$\operatorname{dos}^{21}$. Para responder la duda resulta necesario considerar el destino real de los embriones congelados. Es muy diferente que los embriones sean transferidos a la progenitora o a otra mujer, permitiendo su desarrollo, a que éstos sean donados para ser usados en investigación o entrenamiento de profesionales, porque en esos casos son tratados como mero material biológico. Si los embriones son desechados, por abandono o decisión de sus progenitores, queda claro que no se les respeta ni se les protege. Por último, como ocurre muy frecuentemente, si los embriones son mantenidos indefinidamente congelados, resulta difícil aceptar este trato como respetuoso. Los documentos que defienden el respeto al embrión preimplantacional por su condición de vida humana con una significación especial, pero a la vez no ponen objeciones al desecho, congelamiento indefinido o donación de embriones, se contradicen en su planteamiento ${ }^{19}$.

\section{Conclusiones}

Como se ha descrito más arriba, las FIV/ICSI con criopreservación de embriones tienen claros beneficios para la madre en cuanto a riesgos y costos, pero las tasas de recién nacidos no son en definitiva tan diferentes entre los centros que recurren y los que no recurren a la criopreservación. Sin embargo, hay diferencias importantes en el 
riesgo de multigestación y en los riesgos maternos de repetir ciclos de estimulación ovárica. Por estas razones, la criopreservación de embriones humanos es actualmente una técnica generalizada. Pero una consecuencia de esta práctica es el alto número de embriones que se desechan o que se mantienen congelados de manera indefinida. Pocos centros han comunicado el número de embriones desechados o congelados y las regulaciones más recientes, reconociendo este problema, buscan reducir su número ${ }^{22,23}$. No obstante, los reparos éticos subsisten porque, si verdaderamente se pretende cumplir con el deber moral de respeto y protección al embrión humano, no basta con reducir el número de embriones sobrantes.

Las decisiones en esta materia se presentan en tres niveles diferentes: la mujer o pareja que busca tratamiento, las normas de cada institución, y la legislación de los países. En cada uno de estos niveles de decisión se asume necesariamente, aunque sea de manera implícita, una posición sobre el estatuto moral y sobre el respeto debido al embrión preimplantacional. Si se elude esta definición previa de quienes deciden, el fundamento de la decisión será siempre débil y a la larga confuso.

La opinión médica mayoritaria, a la luz de los resultados internacionales de eficiencia de los ciclos de FIV/ICSI y considerando necesario evitar la multigestación, acepta como válida la criopreservación, tendiendo últimamente a reducir el número de embriones. Este criterio ha demostrado una reducción sustancial del embarazo múltiple y una reducción de costos que permite aumentar el acceso a estos tratamientos.

La decisión de cada pareja ha de ser enteramente libre, basada en sus valores y criterios, para lo cual el esfuerzo de los profesionales tratantes ha de ser evitar toda forma de consejos directivos. Este es el verdadero respeto a la autonomía de sus decisiones, más allá de cualquier tipo de documento de consentimiento informado. Las parejas que deciden deben plantearse, además, el tema del significado que tendrá para ellos tener embriones criopreservados, materia en la cual su representación psicológica es compleja y evolutiva en el tiempo ${ }^{24}$.

Las normas institucionales han de ser claras y conocidas por los usuarios tanto en sus aspectos formales como en sus fundamentos. Para establecerlas se requieren criterios éticos alcanzados mediante procesos deliberativos entre los espe- cialistas, los cuerpos directivos de cada establecimiento y los comités de ética institucionales, considerando, junto a la eficiencia de las técnicas, el total de responsabilidades en juego.

Llevado al terreno de la legislación, se debe asumir la necesidad de legislar con sólidos fundamentos científicos y éticos, y no sólo en base a argumentos de utilidad y eficiencia. Una política legislativa sobre esta materia debe asumir una posición ante los conflictos de valor entre la protección del embrión preimplantacional y el derecho a la autonomía reproductiva de la mujer o pareja. Sin duda, el legislador ha de plantearse al menos la existencia de situaciones de excepción en las que la criopreservación embrionaria podría ser necesaria, tales como la mujer a quien no se le pueda efectuar la transferencia por razones de salud o debido a su fallecimiento, la mujer que revoca su consentimiento antes de la transferencia, o casos de diagnóstico genético preimplantacional para detectar en el embrión enfermedades hereditarias graves o una alteración incompatible con su vida.

En síntesis, se propone la necesidad de analizar y reflexionar con la máxima profundidad los aspectos clínicos, éticos y jurídicos antes de tomar decisiones personales, institucionales o legales para criopreservar embriones humanos, habida consideración de su naturaleza o estatuto moral y del hecho que la destrucción o la criopreservación indefinida son destinos que deben ser evitados.

\section{Referencias}

1. Steptoe P, Edwards R. Birth after the implantation of a human embryo. Lancet 1978; 312 (8085): 366.

2. Trounson A, Mohr L. Human pregnancy following cryopreservation, thawing and transfer of an eight-cell embryo. Nature 1983; 305 (5936): 707-9.

3. Devroey P, Fauser B, Diedrich K. Approaches to improve the diagnosis and management of infertility. Hum Reprod Update 2009; 15 (4): 391-408.

4. Practice Committee of the Society for Assisted Reproductive Technology and the Practice Committee of the Society for Assisted Reproductive Technology. Elective single-embryo transfer. Fertil Steril 2012; 97 (4): 835-42.

5. Edgar D, Gook D. A critical appraisal of cryopreservation (slow cooling versus vitrification) of human oocytes and embryos. Hum Reprod Update 2012; 18 (5): 536-54.

6. Ferrareti A, Goznes V, de Mouzon J, Bhattacharya S, Castilla J, Korsak V, et al. The European IVF-monitoring 
(EIM), and Consortium, for the European Society of Human Reproduction and Embryology (ESHRE), Assisted reproductive technology in Europe, 2008: results generated from European registers by ESHRE. Hum Reprod 2012; 27 (9): 2571-84.

7. Scaravelli G, Vigiliano V, Mayorga J, Bolli S, De Luca R, D'Aloja P. Analysis of oocyte cryopreservation in assisted reproduction: the Italian National Register data from 2005 to 2007. Reprod Biomed Online 2010; 21 (4): 496500.

8. Borini A, Levi Setti P, Anserini P, De Luca R, De Santis L, Porcu E, et al. Multicenter observational study on slowcooling oocyte cryopreservation: clinical outcome. Fertil Steril 2010; 94 (5): 1662-8.

9. Ley de protección de embriones (Embryonen schutzgesetz [ESchG]) de 1990, Alemania; $\$ 1.1 .4$ y $\$ 1-1-5$ (13 de diciembre de 1990).

10. Ley de medicina de la reproducción (Fortpflanzungsmedizingesetz [FMedG]) de 1992, Austria; $\$ 10$ (4 de junio de 1992).

11. Ley $\mathrm{N}^{\circ} 40$ Norme in materia di procreazione medicalmente assistita de 2004, art. 14.2 (19 de Febrero, 1990).

12. Sentencia $N^{\circ} 151 / 2009$ de la Corte Constitucional de la República de Italia.

13. Parlamento Europeo, Resolución $\mathrm{N}^{\circ} 39$ del 16 de marzo de 1989 sobre los problemas éticos y jurídicos de la manipulación genética y Resolución $\mathrm{N}^{\circ} 7$ del 7 de septiembre de 2000 sobre la clonación humana.

14. Proyecto del Senador Piñera de 1993 (Bol. N 1026-07), archivado en el 2002 y desarchivado en el 2006 para ser estudiado conjuntamente con el proyecto del Senador Ruiz-Esquide (Bol. No 4346-11); ambos proyectos terminaron archivados el 2008.

15. Corte IDH. Caso Artavia Murillo y otros (fecundación in vitro) vs Costa Rica. Sentencia 28 de noviembre de 2012. Disponible en http://www.corteidh.or.cr/casos. $\mathrm{cfm}$ ? idCaso $=403$.

16. National Center for Biotechnology Information (NCBI) MeSH Database. Disponible en http://www.ncbi.nlm. nih.gov/mesh/?term=conception.

17. Bedate A. El valor ontológico del embrión humano: una visión alternativa. En: Beca J.P. El Embrión Humano. Santiago, Chile: Editorial Mediterráneo; 2002. p. 51-92.

18. Grupo Interdisciplinario de Bioética. Consideraciones sobre el embrión humano. Bioética \& Debat 2009; 57 : $1-12$.

19. ESHRE Task Force for Ethics and Law. The moral status of the pre-implantation embryo. Human Reproduction 2001; 16: 1046-8.

20. Feito L. Estatuto moral del embrión humano: cuestiones filosóficas y consideraciones morales. En: Beca J.P. y Astete C. Bioética Clínica. Santiago, Chile: Editorial Mediterráneo Ltda.; 2012. p. 281-97.

21. Beca J.P. Ética de las intervenciones médicas en embriones humanos. En: Beca J.P. El Embrión Humano. Santiago, Chile: Editorial Mediterráneo Ltda.; 2002. p. 221-43.

22. Schwarze, J. Registro chileno de técnicas de reproducción asistida, 2010. Registro Chileno de Fecundación in vitro, Sociedad Chilena de Medicina Reproductiva. Rev Chil Obstet Ginecol 2013; 78 (2): 82-7.

23. Pommer R, Arguello B, Díaz-Fontevilla M, Martínez C, Fuentes E, Furman I, et al. Criopreservación de pronúcleos: rol en el programa de fertilización asistida. Rev Chil Obstet Ginecol 2003; 68 (4): 287-92.

24. Klock SC. Embryo disposition: the forgotten "child" of in vitro fertilization. Int J Fertil Womens Med 2004; 49: (1): 19-23. 